\section{User and carer involvement in mental health}

\section{services: from rhetoric to science}

\author{
E. L. SIMPSON and A. O. HOUSE
}

The Department of Health has emphasised the need for a patient-centred National Health Service (NHS), and the involvement of users and carers in mental health services is often a policy recommendation (Mental Health Task Force User Group, 1995; NHS Health Advisory Service, 1997; Department of Health, 1999a,b, 2001). The Patients' Forum and Consumers in NHS Research are established national bodies concerned with stakeholder involvement. The Commission for Patient and Public Involvement in Health was established in 2003.

User or carer involvement is often seen as intrinsically worth while; but if such involvement is a good thing in itself, it would not matter whether changes resulted from it. However, most people argue for user or carer involvement because they think some useful change will follow as a consequence. Being involved can benefit users or carers both personally (for example, by empowering them or increasing their social contacts) and practically (for example, by enabling them to earn money or learn new skills). Improvements can be made to services as a result of involvement, leading to better relationships between users or carers and staff, and perhaps increased job satisfaction among those working in the service. Targeting services to users' needs may improve the cost-effectiveness of those services.

Users or carers can influence health services in more than one way. Consumerism is an approach based on the assumption that users have a choice of services, and through exercising choice can influence service provision. Political activism is a way of working for change by applying external pressure, arguing for legislative change. In self-help, users and carers provide some part of service that is separate from statutory provision. In these approaches, users or carers initiate the activity, which takes place outside the usual mechanisms for planning, delivering or evaluating statutory services.

Stakeholder involvement, on the other hand, is an approach in which participants work within the mental health services as a part of the usual mechanisms of care. Thus, service providers can play an active part in involving users and carers as partners in services. User and carer involvement is formally integrated within the service, actively planning or delivering mental health services, or being involved in evaluation research. Users and carers participate in service decision-making: they are not merely expressing opinions about services. For example, this definition of involvement excludes simply undertaking user satisfaction surveys, since such surveys do not imply a mechanism for feeding user views into planning, or require participation of user or carer stakeholders as partners.

Users and carers have been involved as stakeholders in planning, delivering and evaluating services, mainly - to judge from the literature - in the USA, Canada, Australia and the UK (Simpson et al, 2002). Across the UK, involvement in planning has included consideration of the results of user surveys and the inclusion of users or carers on boards or committees for service planning. Users and carers have been involved in service delivery by collaborating in training or appointing staff, or by working alongside mental health professionals as employees. Research has been conducted that involves users in the design, implementation or dissemination of results.

\section{PRACTICALITIES: BEYOND THE RHETORIC}

When moving beyond stating principles to planning action, there are a number of stages to be considered when involving users or carers as stakeholders in services (discussed in more detail by Simpson et al, 2002):

(a) deciding on the main goal;

(b) choosing a mechanism of involvement to achieve that goal;

(c) identifying potential barriers and solutions (Table 1);

(d) monitoring the process of involvement;

(e) evaluating outcomes of the project, measuring whether the goal has been met;

(f) using data collected to inform running of this and future projects.

A clear idea of what a project is meant to achieve helps to clarify how users and carers should be involved and suggests ways of evaluating the project's effectiveness. Feedback from the evaluation should be given to participants and could be used to improve future user and carer involvement.

Several factors can hinder user and carer involvement (Table 1). These will affect the choice of method of involvement and suggest forms of support needed for projects. Taking such potential barriers into account prior to setting up a project can improve its chance of success (NHS Centre for Reviews and Dissemination, 1999). There will be other practical issues to consider, such as resource allocation, payment to users, methods of conflict resolution and legal or ethical issues such as confidentiality.

\section{EVIDENCE: WHAT DO WE KNOW ABOUT THE EFFECTS OF USER INVOLVEMENT?}

Few comparative studies have been published. Those that have been (summarised by Simpson \& House, 2002) cover the involvement of users as service employees, trainers of mental health service professionals and research interviewers. These studies suggest that trained users with quite severe disorders, including schizophrenia and bipolar disorder, can be employed effectively in mental health service provision. Their roles within clinical teams have concentrated on engaging, and organising the care of, other service users, rather than delivering therapies. Support was provided to user employees, consisting of training, payment and practical advice from colleagues.

User employees differ from non-user employees in how they work, for example 
by doing more outreach work, having more face-to-face contacts with users receiving services, or working with less distinct employee-user boundaries. Studies indicate that employing users in case management or outreach services does not damage these services; there are suggestions that the users they work with have fewer hospital admissions and improved aspects of quality of life.

User involvement in training may influence trainees' attitudes, leading to a more positive attitude towards user employees, or a more individualised approach to assessment of users. When users have been research interviewers of other service users, there was lower reported satisfaction with services, which has been interpreted as enhanced validity.

The evidence is not conclusive. Of the 12 studies we found, only 5 were randomised trials. Each involved few users (no more than eight at one time), making it outcome measures were adapted for the difficult to generalise results. Many

E. L. SIMPSON, PhD, A. O. HOUSE, MRCPsych, Academic Unit of Psychiatry and Behavioural Sciences, University of Leeds, UK

Correspondence: E. L. Simpson, Academic Unit of Psychiatry and Behavioural Sciences, University of Leeds, 15 HydeTerrace, Leeds LS2 9LT, UK

(First received 30 August 2002, final revision 14 November 2002, accepted 4 December 2002) specific study and few were assessed independently. Half the studies concerned intensive case management services, in North America or Australia, which are not widely used elsewhere. Research on user involvement is not straightforward. Large sample sizes may be difficult to obtain and there may be a reluctance to accept services from user employees. Users may not be involved throughout the whole study period. However, evidence from noncomparative research also indicates few disadvantages and some possible advantages from user involvement in service delivery and research. It is worth noting
Table I Examples of factors that might inhibit user or carer involvement projects, and some potential solutions

\begin{tabular}{|c|c|}
\hline Barriers & Possible solutions \\
\hline $\begin{array}{l}\text { Questioning whether users or } \\
\text { carers involved are } \\
\text { representative }\end{array}$ & $\begin{array}{l}\text { Accept unrepresentativeness if any relevant experience is needed; } \\
\text { or accept partial representativeness by careful selection of only } \\
\text { particular stakeholders (users and carers do not make good } \\
\text { proxies for each other, as they may have different agendas); or } \\
\text { appoint participants to be accountable to other stakeholders }\end{array}$ \\
\hline $\begin{array}{l}\text { Lack of interest from users and } \\
\text { carers }\end{array}$ & $\begin{array}{l}\text { Widen sources of recruitment, for instance by contacting voluntary } \\
\text { organisations. Target difficult-to-reach groups by advertising in a } \\
\text { range of languages or formats }\end{array}$ \\
\hline $\begin{array}{l}\text { Tokenism - few users and carers } \\
\text { involved, or involvement in } \\
\text { only trivial tasks }\end{array}$ & $\begin{array}{l}\text { Alleviate providers' doubts about the usefulness of user and carer } \\
\text { involvement, by having a clear, reachable aim, and monitoring the } \\
\text { project. Set-up agreed procedures for incorporating user and } \\
\text { carer views into decision-making processes of organisation }\end{array}$ \\
\hline $\begin{array}{l}\text { Concern about users' ability to } \\
\text { make rational contributions }\end{array}$ & $\begin{array}{l}\text { Some disorders may preclude participation, if they impair cognitive } \\
\text { or communication skills, but the users' involvement could be } \\
\text { achieved (for example) through advocacy }\end{array}$ \\
\hline $\begin{array}{l}\text { Stress of involvement may } \\
\text { damage users' mental health }\end{array}$ & Provide clinical support \\
\hline $\begin{array}{l}\text { User and carer stakeholders' lack } \\
\text { of experience }\end{array}$ & Provide training and information to enable participation \\
\hline Communication barriers & $\begin{array}{l}\text { Limit use of jargon. Long-term discussion groups can ease } \\
\text { communication }\end{array}$ \\
\hline $\begin{array}{l}\text { Role strain (difficulty } \\
\text { relinquishing patient or } \\
\text { healer role }\end{array}$ & User and professional training \\
\hline
\end{tabular}

that effects on users involved, although not extensively evaluated, have generally been reported as positive. We found little research on involvement in planning, but limited effectiveness of user involvement in planning teams or mental health forums has been reported (Milewa, 1997).

\section{THE FUTURE}

Mechanisms for involving users or carers can be thought of as health technologies (Simpson et al, 2002). Service providers could think about involving users and carers in much the same way as any health service intervention. This perspective encourages a rigorous approach to identifying aims for user involvement, then choosing and implementing an approach designed to achieve those aims, and monitoring to see if the aims have been achieved.

User or carer involvement may not lend itself to conventional study by randomised controlled trials. This suggests a need for other forms of study. One way to gain evidence is through monitoring of routine data on user or carer involvement projects. We should not give up the task of undertaking formal research evaluations of user projects. The literature tells us that, under the right circumstances, even conventional randomised controlled trials are possible.

Building on the existing evidence from research into user or carer involvement should encourage involvement to be taken seriously, as a scientifically sound method of influencing service provision. There is a need to allocate funding, not just to setting up user involvement technologies but to monitoring and researching them, and ensuring that effective projects are sustained.

\section{DECLARATION OF INTEREST}

None. 


\section{ACKNOWLEDGEMENTS}

Funding for the literature review of user involvement in mental health services was provided by Leeds Mental Health Teaching NHS Trust (formerly Leeds Community and Mental Health Services Trust).

\section{REFERENCES}

Department of Health (1999a) National Service Framework for Mental Health: Modern Standards and Service Models. London: Department of Health.
- (1999b) Patient and Public Involvement in the New NHS. London: Department of Health.

- (200I) Involving Patients and the Public in Healthcare: A Discussion Document. London: Department of Health.

Mental Health Task Force User Group (1995) Forging Our Futures: Lighting the Fire. London: Mental Health Task Force User Group.

Milewa, T. (1997) Community participation and health care priorities: reflections on policy, theatre and reality in Britain. Health Promotion International, 12, 161-168.

NHS Centre for Reviews and Dissemination (1999) Getting evidence into practice. Effective Health Care, $\mathbf{5}$, $1-16$.
NHS Health Advisory Service (1997) Voices in Partnership: Involving Users and Carers in Commissioning and Delivering Mental Health Services. London: Stationery Office.

Simpson, E. L. \& House, A. O. (2002) Involving user in the delivery and evaluation of mental health services: systematic review. BMJ, 325, 1265-1267.

_ \& Barkham, M. (2002) A Guide to Involving Users, Ex-users and Carers in Mental Health Service Planning, Delivery or Research: A Health Technology Approach. Leeds: Academic Unit of Psychiatry and Behavioural Sciences, University of Leeds. 